\title{
Genotypic and Environmental Variation in Antioxidant Activity and Total Phenolic Content among Blackberry and Hybridberry Cultivars
}

\author{
Ann Marie Connor \\ HortResearch-Ruakura Research Centre, Private Bag 3123, Hamilton, New Zealand \\ Chad E. Finn \\ U.S.Department of Agriculture-Agricultural Research Service, Horticultural Crops Research Laboratory, \\ 3420 NW Orchard Avenue, Corvallis, OR 97330
}

Peter A. Alspach

HortResearch-Nelson Research Centre, P.O. Box 220, Motueka, New Zealand

AdDitional INDEX WORDs. Rubus species, phenotypic correlation, berry weight

\begin{abstract}
Antioxidant compounds absorbed from our diet are thought to have a role in preventing chronic diseases that result from oxidative damage. Berry fruit have high levels of antioxidants, and further increases in antioxidant activity (AA) might be possible through breeding. We determined the AA, total phenolic content (TPH), and fruit weight in 16 blackberry and hybridberry (Rubus L.) cultivars harvested in New Zealand and Oregon in 2002 and 2003 , to assess genetic and environmental variation. Both AA and TPH varied significantly between years within location, but not among cultivars or between locations per se. However, cultivar interactions with both location and year within location contributed to variation in both variates. In contrast, both cultivar and location contributed to variation in fruit weight, but years within location did not. However, the cultivar $\times$ year within location interaction was significant for this trait. Variance component distributions confirmed that cultivar and location effects together contributed little $(<20 \%)$ to the total variation in either AA or TPH, while cultivar $x$ environment interactions accounted for $>50 \%$ of total variation in these traits. Cultivar and location effects together contributed $\approx 70 \%$ of the total variation observed in fruit weight. Phenotypic correlations were significant between AA and fruit weight $(r=-0.44)$, and between TPH and fruit weight $(r=-0.51)$. When adjusted for fruit weight, analyses for AA and TPH demonstrated that cultivar effects approached significance $(P=\mathbf{0 . 0 6})$ and accounted for $\approx 25 \%$ of total variance, while location effects accounted for none. Although the cultivars in this study had diverse interspecific backgrounds, utilization of various Rubus species in blackberry and hybridberry breeding is not uncommon, and our results demonstrating significant cultivar $\times$ environment interaction for AA and TPH should be applicable to breeding for high AA genotypes.
\end{abstract}

Greater consumption of fresh fruit and vegetables has been encouraged in recent years because their intake has been linked to lower risk of cardiovascular diseases (Bazzano et al., 2002; Joshipura et al., 1999, 2001; Ness and Powles, 1997, 1999; Sauvaget et al., 2003), cancer (Block et al., 1992; Miller et al., 2004; Smith-Warner et al., 2003; Steinmetz and Potter, 1991, 1996), degenerative eye diseases (Brown et al., 1999; Cho et al., 2004; Goldberg et al., 1988), and other chronic and degenerative diseases that occur frequently in industrialized countries. One of the mechanisms that appears to be important in the development of many degenerative diseases is oxidative stress, induced by free radical attack on cellular components by active oxygen species. Consequently, antioxidants, which prevent oxidative stress, are considered important in reducing the initiation and progression of these diseases. Our endogenous antioxidant systems serve a major role in combating oxidative stress (Cotran et al., 1999), but we also obtain effective antioxidants through our diets. Fruit and vegetables are excellent sources of antioxidant phytochemicals, such as the carotenoids, vitamins $\mathrm{C}$ and $\mathrm{E}$, folate, and thiol compounds. Their antioxidant activity (AA) might help explain the link between increased fruit and vegetable consumption and lower risk of chronic diseases. In contrast to animal food sources, plant foods also contain many simple phenolic and polyphenolic

Received for publication 28 Nov. 2004. Accepted for publication 29 Jan. 2005. We thank Mary Peterson for technical assistance and Harvey Hall for access to the blackberry and hybridberry germplasm collection at HortResearch. compounds that possess significant AA. The polyphenolic compounds are chemically diverse and, in plants, they serve a number of eco-physiological roles, including responses to disease or other stress. As components in the human diet, the phenolic compounds are hypothesized to function as antioxidants directly, or to influence the production or function of other antioxidant compounds in the body. Since berry fruit (including Rubus species) contain high concentrations of several classes of phenolic compounds, including phenolic acids, anthocyanins, and flavonols (Häkkinen et al., 1999; Herrmann, 1989; Kähkönen et al., 2001, Proteggente et al., 2002), these compounds appear to account for the high in vitro AA found in many berry extracts (Halvorsen et al., 2002)., even as compared to other fruit, which are considered excellent sources of AA (Halvorsen et al., 2002; Kähkönen et al., 1999; Wang et al., 1996).

As more consumers in industrialized nations consume healthier diets with more fruit and vegetables, worldwide production is necessary to satisfy increasing demand and provide year-round availability. Successful production depends on having cultivars adapted to the target growing regions. Cultivar development programs typically assess performance and adaptability of selections over several locations and years, but economic constraints limit the environments in which a selection can be tested. Programs developing cultivars with higher levels of healthful compounds can better anticipate the extent of testing required to accurately assess the trait(s) if estimates of genotypic and environmental 
variation are available. In this study, we report the genotypic and environmental variation in AA, total phenolic content (TPH), and fruit weight among blackberry and hybridberry cultivars grown in the northern (Oregon, United States) and southern (South Island, New Zealand) hemispheres where breeding programs are maintained. Variation in AA and TPH among hybrid blackberry cultivars has been reported previously (Clark et al., 2002; Moyer et al., 2002; Sellapan et al. 2002; Wada and Ou, 2002; Wang and Lin, 2000), although in most of these studies only a small number of cultivars were examined. The largest of these studies (Moyer et al., 2002) reported AA, TPH, and anthocyanin content in fruit from 37 Rubus species and cultivars, including 27 hybrid blackberry genotypes and five species of blackberries harvested in a single year. They noted the significant and generally high correlations between AA and TPH. They also reported no significant correlation between fruit size (fruit/100 g) and anthocyanin content among the hybrid blackberries, but found a correlation $(r=0.45)$ between size and anthocyanin content when all 37 Rubus species and cultivar genotypes were considered. Clark et al. (2002) included fewer blackberry genotypes (13-15), but examined differences in AA, TPH, and anthocyanin content between two growing seasons. Some genotypes demonstrated little change between years, while others showed marked differences. The current investigation differs from the previous reports in that it examines the effects of location and year on the AA, TPH, and fruit weight among 12-16 blackberry and hybridberry cultivars. For clarity, the term "blackberry" is used here to refer to those genotypes whose known or presumed ancestries include species from Rubus blackberry subgenera only, while "hybridberry" refers to those whose ancestral species are not purely from blackberry subgenera. In the botanical sense, all cultivars included in this study are "blackberries" in that the receptacles remain with the detached fruit.

\section{Materials and Methods}

Plants. Genotypes were selected on the basis of their availability and ability to yield a sufficient sample of fruit for both years of the study (2002-03, designated 2002; and 2003-04, designated 2003). In New Zealand, plants were grown in a research orchard at HortResearch-Nelson Research Centre in Motueka (lat. $41^{\circ} 6^{\prime} \mathrm{S}$ ). Plants were grown in rows in a single block protected by bird-proof netting and were trained to a four-wire trellis system. Single plants were harvested for each genotype in both years. Spacing was $1.5 \mathrm{~m}$ between plants and $3 \mathrm{~m}$ between rows. Fertilization, weed control, and irrigation practices standard for the region were provided both seasons. Floricanes were trained to wires during the dormant season, and were removed following the fruiting season. In Oregon, the plants were grown in a research orchard at the North Willamette Experiment Station in Aurora (lat. $45^{\circ} 23^{\prime} \mathrm{N}$ ). Plant spacing and training were similar to that in New Zealand, but no netting protection was used. For each genotype, fruit were harvested from one to three plants within a single plot in both years.

FruIT. Approximately $100 \mathrm{~g}$ of shiny black, ripe, sound fruit were collected when $\approx 50 \%$ of the fruit on the plant were fully ripe. Overripe fruit (dull black) were avoided. Experienced individuals at both sites performed the harvests, to assure that the fruit were collected at the same stage of ripeness. Of the 16 cultivars selected for study, 12 were successfully harvested in both years at both locations. In New Zealand, fruit were held 1-3 h at ambient field temperature $\left(\approx 11-13^{\circ} \mathrm{C}\right)$ in the shade in plastic punnets prior to being weighed, counted, and stored in sealed plastic bags at -20 ${ }^{\circ} \mathrm{C}$ (in 2002) or $-40{ }^{\circ} \mathrm{C}$ (in 2003). Six to 8 weeks later they were transferred on dry ice without thawing to laboratory facilities where they were held at $-85^{\circ} \mathrm{C}$ until extraction. Fruit collected in Oregon were held in plastic bags on wet ice in insulated containers for $1-4 \mathrm{~h}$ in the field, until weighing and freezing at -40 ${ }^{\circ} \mathrm{C}$. After 6 to 8 weeks, they were shipped on dry ice without thawing to the laboratory facilities in New Zealand and held at $-85^{\circ} \mathrm{C}$ until extraction.

Extraction. Extractions were conducted under reduced light conditions or under safety-light in a fume hood. Approximately $30 \mathrm{~g}$ of frozen fruit were weighed, counted, and placed in $250-\mathrm{mL}$ glass screw-cap bottles to which $150 \mathrm{~mL}$ solvent (80 ethanol : 20 water : 1 glacial acetic acid, by volume) was added; fruit collected from Oregon in 2002 were extracted in a ratio of $20 \mathrm{~g}$ fruit to 100 $\mathrm{mL}$ solvent. The mixture was homogenized at highest speed for 1 min using an Ultra-Turrax (T 25 basic; IKA Works, Selangor, Malaysia). The homogenate was stored in tightly capped bottles for $48 \mathrm{~h}$ at $4{ }^{\circ} \mathrm{C}$, at which time it was mixed briefly and allowed to equilibrate toward room temperature $\left(\approx 18^{\circ} \mathrm{C}\right)$ for $1 \mathrm{~h}$. Two 10-mLaliquots of the homogenate were removed to separate glass screw-cap tubes and centrifuged at room temperature for $20 \mathrm{~min}$ at $1500 g_{n}$ (Labofuge GL; Heraeus Christ, Osterode, Germany). Approximately $4 \mathrm{~mL}$ of supernatant was removed from each aliquot and stored in separate amber screw-cap glass vials at -20 ${ }^{\circ} \mathrm{C}$ until assayed. Extractions were performed in duplicate, giving four aliquots for each genotype.

Total PHENOLIC CONTENT. A modification of the Folin-Ciocalteu reagent-based method by Coseteng and Lee (1987) was used, allowing $90 \mathrm{~min}$ for color development. Single determinations were performed on each aliquot from each extract, since preliminary work showed that variation between determinations on a single aliquot was negligible (data not shown). Results are expressed as gallic acid equivalents (GAE) in milligrams per $100 \mathrm{~g}$ fruit.

Antioxidant ACTIVITy. The ferric-reducing antioxidant power (FRAP) assay (Benzie and Strain, 1996; also referred to as the "ferric-reducing activity of plasma") was used, with modifications by Deighton et al. (2000). After the addition of diluted extract or standard to the FRAP reagent, absorbance of the colored product [ferrous tripyridyltriazine (TPTZ) complex] at $593 \mathrm{~nm}$ was recorded at exactly 4 min (DU-640 spectrophotometer; Beckman, Fullerton, Calif.). Standard curves using Trolox (0-250 $\mu \mathrm{M})$ and ferrous sulphate $(0-500 \mu \mathrm{M})$ were determined separately with each assay and both were linear within their respective ranges. The ferric-reducing activity of Trolox was approximately twice that of ferrous sulphate, which concurs with Benzie and Strain (1996). Single determinations were performed on each aliquot from each extract, since preliminary work showed that variation between determinations on a single aliquot was negligible (data not shown). Results are expressed as micromoles of ferrous sulphate equivalents (FE) per gram of fruit.

Statistical AnAlyses. Analyses of variance (ANOVAs) and variance component analyses were performed with cultivars, locations, years, extracts, and aliquots treated as random effects. Years were nested within locations, and extracts within cultivars. Restricted maximum likelihood was used to estimate variance components. ANOVAs and variance components analyses were based on the 12 cultivars common to both locations in both years. The cultivar means, over years and locations, were used in calculating phenotypic correlations. Satterthwaite's (1946) approximation for denominator degrees of freedom, as described by Steel et al. (1997), was used where required. Analyses were 
performed using S-Plus software (version 6.1.2, release 1 for Microsoft Windows; Insightful Corp., Seattle, Wash.)

\section{Results}

Mean AA, TPH, and fruit weight for the cultivars harvested at each location in 2002 and 2003 are shown in Table 1. For each location, mean AA and TPH over the 12 common cultivars was lower in 2003 than 2002. The ranges in TPH among the 12 cultivars were similar in degree to those in AA in the respective locations and years. The within-year differences in fruit weight of the 12 cultivars were similar to, or perhaps slightly greater than, those for AA and TPH at each location, given the difference in scale.

Of the four additional cultivars that were not harvested from both sites in both years of the study, 'Chehalem' was distinguished by its high AA and TPH and low berry weight. In New Zealand (NZ), it showed the highest AA and TPH of all genotypes measured in 2002, while in Oregon (OR), it showed the second-highest AA and highest TPH values in 2003. In both circumstances, it also had the lowest fruit weight. Inclusion of the four additional cultivars did not substantially change the overall means for AA, $\mathrm{TPH}$, or fruit weight within each location.
ANOVAs of the combined-year data reflected some of the changes in traits between years and locations that were noted above. Cultivar and location effects on AA were not significant in the combined year analyses (Table 2); ANOVAs for individual year data demonstrated significant variation between locations only in 2003 ( $P=0.043$ ) for AA (analysis not shown). However, significant variation in mean AA for all cultivars occurred between years within location. Additionally, cultivar $\times$ location and cultivar $\times$ year within location interactions for AA were significant, indicating a substantial change in rank or scale occurred among cultivars assessed in different environments. Changes in AA between years for individual cultivars ranged from an increase of $7.1 \mu \mathrm{mol} \cdot \mathrm{g}^{-1}$ fruit ('Shawnee') to a decrease of $18.0 \mu \mathrm{mol} \cdot \mathrm{g}^{-1}$ fruit ('Siskiyou') in NZ; and an increase of 7.2 $\mu \mathrm{mol} \cdot \mathrm{g}^{-1}$ fruit ('Boysen') to a decrease of $20.8 \mu \mathrm{mol} \cdot \mathrm{g}^{-1}$ fruit ('Tayberry') in OR. 'Shawnee' and 'Siskiyou' illustrate the rank changes that occurred between years in NZ. 'Shawnee' fruit ranked 12th (i.e., bottom) in AA in 2002, but was sixth equal in 2003. Conversely, 'Siskiyou' fruit displayed the second-highest level of AA in 2002, but was only fifth in 2003. Note that when harvested in OR, 'Siskiyou' ranked seventh in AA concentration in 2002 but fourth in 2003, despite its AA increasing by only 1.8 $\mu \mathrm{mol} \cdot \mathrm{g}^{-1}$ fruit between years.

Table 1. Mean antioxidant activity [AA in $\mathrm{FeSO}_{4}$ equivalents (FE)], total phenolic content (TPH), and fruit weight of 12 blackberry and hybridberry cultivars harvested in Oregon (OR) and New Zealand (NZ) in 2002 and 2003. Cultivars listed in increasing order of mean TPH (upper table). Mean values of AA, TPH, and fruit weight for additional cultivars and selections not harvested at both locations in both years (lower table).

\begin{tabular}{|c|c|c|c|c|c|c|c|c|c|c|c|c|c|c|c|}
\hline \multirow[b]{3}{*}{ Cultivar } & \multicolumn{5}{|c|}{$\mathrm{AA}\left(\mathrm{FE} \mu \mathrm{mol} \cdot \mathrm{g}^{-1}\right.$ fruit $)$} & \multicolumn{5}{|c|}{$\mathrm{TPH}$ (mg/100 g fruit) } & \multicolumn{5}{|c|}{ Fruit wt $(\mathrm{g})$} \\
\hline & \multicolumn{2}{|c|}{$\mathrm{NZ}$} & \multicolumn{2}{|c|}{ OR } & \multirow[b]{2}{*}{ Mean } & \multicolumn{2}{|c|}{$\mathrm{NZ}$} & \multicolumn{2}{|c|}{ OR } & \multirow[b]{2}{*}{ Mean } & \multicolumn{2}{|c|}{$\mathrm{NZ}$} & \multicolumn{2}{|c|}{ OR } & \multirow[b]{2}{*}{ Mean } \\
\hline & 2002 & 2003 & 2002 & 2003 & & $\underline{2002}$ & 2003 & 2002 & 2003 & & 2002 & 2003 & 2002 & 2003 & \\
\hline Shawnee & 49.0 & 56.1 & 58.7 & 51.2 & 53.8 & 323 & 400 & 404 & 363 & 373 & 9.05 & 7.05 & 6.26 & 7.75 & 7.53 \\
\hline Tayberry & 52.1 & 40.0 & 79.1 & 58.3 & 57.4 & 347 & 248 & 549 & 422 & 392 & 6.89 & 7.57 & 4.24 & 2.91 & 5.40 \\
\hline Hull Thornless & 63.5 & 54.6 & 62.2 & 43.3 & 55.9 & 444 & 406 & 453 & 318 & 405 & 6.21 & 7.89 & 5.35 & 6.27 & 6.43 \\
\hline Logan & 67.1 & 56.0 & 71.7 & 63.3 & 64.5 & 441 & 356 & 482 & 439 & 429 & 4.81 & 6.14 & 4.58 & 4.34 & 4.97 \\
\hline Black Butte & 69.4 & 63.8 & 60.6 & 66.6 & 65.1 & 464 & 421 & 409 & 464 & 439 & 11.24 & 10.55 & 10.73 & 7.89 & 10.10 \\
\hline Ranui & 68.3 & 56.1 & 70.5 & 75.1 & 67.5 & 445 & 382 & 484 & 507 & 454 & 10.22 & 10.15 & 7.54 & 5.72 & 8.40 \\
\hline Navaho & 72.2 & 63.1 & 61.0 & 55.8 & 63.0 & 517 & 465 & 440 & 413 & 459 & 6.23 & 6.93 & 5.58 & 6.15 & 6.22 \\
\hline Silvan & 67.8 & 52.8 & 79.8 & 62.4 & 65.7 & 465 & 374 & 549 & 452 & 460 & 7.58 & 9.11 & 4.37 & 7.32 & 7.09 \\
\hline Siskiyou & 74.2 & 56.2 & 71.5 & 73.3 & 68.8 & 501 & 367 & 492 & 489 & 463 & 9.13 & 9.01 & 7.92 & 8.04 & 8.52 \\
\hline Kotata & 60.4 & 52.2 & 83.0 & 78.4 & 68.5 & 397 & 362 & 555 & 541 & 464 & 6.18 & 7.56 & 4.92 & 4.21 & 5.71 \\
\hline Marion & 81.0 & 70.4 & 80.8 & 70.2 & 75.6 & 542 & 483 & 540 & 487 & 513 & 6.02 & 7.82 & 6.19 & 5.25 & 6.32 \\
\hline Boysen & 70.7 & 57.8 & 82.6 & 89.8 & 75.2 & 536 & 372 & 633 & 604 & 536 & 5.78 & 9.13 & 5.08 & 7.13 & 6.78 \\
\hline $\begin{array}{l}\text { Yearly means } \\
\text { (12 cultivars) }\end{array}$ & $\underbrace{66.3}$ & $\begin{array}{r}56.6 \\
\end{array}$ & $\underbrace{71.8}$ & $\begin{array}{r}65.6 \\
\end{array}$ & & $\underbrace{452}$ & $\begin{array}{r}386 \\
\end{array}$ & $\underbrace{499}$ & $\begin{array}{r}458 \\
-\end{array}$ & & $\underbrace{7.44}$ & $\stackrel{8.24}{-}$ & $\underbrace{6.06}$ & $\begin{array}{r}6.08 \\
\end{array}$ & \\
\hline $\begin{array}{l}\text { Location means } \\
\text { (12 cultivars) }\end{array}$ & 61 & & 68 & & & 41 & & 47 & & & & .84 & & 5.07 & \\
\hline Chehalem & 94.2 & $\begin{array}{l}--- \\
\end{array}$ & $\begin{array}{l}--- \\
\end{array}$ & 87.7 & 91.0 & 603 & $\begin{array}{l}--- \\
\end{array}$ & ---- & 614 & 609 & 3.35 & ---- & ---- & 2.56 & 2.95 \\
\hline ORUS 1826 & 66.5 & 56.6 & ---- & ---- & 61.5 & 438 & 349 & ---- & ---- & 394 & 9.32 & 10.54 & ---- & ---- & 9.93 \\
\hline Aurora & 70.2 & 54.5 & 85.2 & ---- & 70.0 & 467 & 367 & 568 & ---- & 467 & 6.42 & 9.04 & 5.22 & ---- & 6.89 \\
\hline Waldo & --- & ---- & 79.4 & 69.0 & 74.2 & --- & ---- & 557 & 479 & 518 & ---- & ---- & 5.43 & 6.39 & 5.91 \\
\hline $\begin{array}{l}\text { Yearly means } \\
\text { (all cultivars) }\end{array}$ & $\underbrace{68.4}$ & $\begin{array}{r}56.4 \\
\end{array}$ & $\underbrace{73.6}$ & $\begin{array}{r}67.5 \\
\end{array}$ & & $\underbrace{462}$ & $\begin{array}{r}383 \\
\end{array}$ & $\underbrace{508}$ & $\begin{array}{r}471 \\
\end{array}$ & & $\underbrace{7.23}$ & $\underbrace{8.46}$ & $\underbrace{5.96}$ & $\underbrace{5.85}$ & \\
\hline $\begin{array}{l}\text { Location means } \\
\text { (all cultivars) }\end{array}$ & 62 & & 70 & & & 42 & & 49 & & & & .82 & & 5.90 & \\
\hline
\end{tabular}


Table 2. Analyses of variance for antioxidant activity among 12 blackberry and hybridberry cultivars harvested in New Zealand and Oregon in 2002 and 2003, without and with fruit weight as a covariate.

\begin{tabular}{lccrrrrrr}
\hline & \multicolumn{3}{c}{ Mean } & \multicolumn{5}{c}{ Mean } \\
Source & df & squares & F & $P$ & df & squares & F & $P$ \\
\hline Fruit weight & -- & ----- & ---- & ---- & 1 & 2174 & 4452.08 & $<0.001$ \\
Cultivar (C) & 11 & 758 & 1.48 & 0.265 & 11 & 1070 & 2.70 & 0.057 \\
Location (L) & 1 & 2530 & 1.29 & 0.339 & 1 & 8 & 0.01 & 0.941 \\
Year (Y) within L & 2 & 1586 & 11.97 & 0.003 & 2 & 1024 & 9.02 & 0.001 \\
C $\times$ L & 11 & 514 & 3.88 & 0.003 & 11 & 396 & 3.49 & 0.006 \\
C $\times$ Y within L & 22 & 132 & 6.42 & $<0.001$ & 22 & 113 & 7.21 & $<0.001$ \\
Extract within C $\times$ Y within L & 48 & 21 & 42.23 & $<0.001$ & 47 & 16 & 32.23 & $<0.001$ \\
Residuals & 96 & 0.49 & & & 96 & 0.49 &
\end{tabular}

Variation in TPH was also present between years within location, and in cultivar $\times$ location and cultivar $\times$ year within location interactions (Table 3 ). The decreases in yearly means noted in both locations were significant: from $452 \mathrm{mg} / 100 \mathrm{~g}$ fruit (2002) to $386 \mathrm{mg} / 100 \mathrm{~g}$ fruit (2003) in NZ and from $499 \mathrm{mg} / 100 \mathrm{~g}$ fruit (2002) to $458 \mathrm{mg} / 100 \mathrm{~g}$ fruit (2003) in OR. Cultivar changes in rank or scale between years and between locations were noted for TPH as well as AA. For example, for individual cultivars in NZ, changes in TPH between years ranged from an increase of 77 $\mathrm{mg} / 100 \mathrm{~g}$ fruit ('Shawnee') to a decrease of $164 \mathrm{mg} / 100 \mathrm{~g}$ fruit ('Boysen'). Similarly, for fruit from OR, changes in TPH between years ranged from an increase of $55 \mathrm{mg} / 100 \mathrm{~g}$ fruit ('Black Butte') to a decrease of $135 \mathrm{mg} / 100 \mathrm{~g}$ fruit ('Hull Thornless'). Variation among cultivars and variation in mean TPH between locations were not significant in the combined year analyses, but as with AA, there was significant variation between locations $(P=0.031$; analysis not shown) when data from 2003 alone were analyzed. For AA and TPH, between-extract variation was small but statistically significant as compared to that between aliquots.

In contrast to the ANOVAs for AA and TPH, the ANOVA for fruit weight indicated that the variation observed among cultivars and between locations was significant, but that the between-year variation in the mean fruit weight for all cultivars within a location was not (Table 4). The between-year variation in fruit weight of individual cultivars, however, was substantial but inconsistent among cultivars, as indicated by the significant cultivar $\times$ year within location interaction.

A very high positive correlation existed between TPH and AA $(r=0.97, P<0.001)$, while negative correlations of lower magnitude were noted between AA and fruit weight $(r=-0.44$, $P<0.001)$ and between TPH and fruit weight $(r=-0.51, P<$
0.001). Variation in fruit weight, then, could account for some of the observed variation in AA and TPH. Repeat ANOVAs for AA and TPH adjusted for fruit weight (Tables 2 and 3 ) show that this covariate was indeed significant and that variation in AA and TPH among cultivars approached significance when adjustment for fruit weight was made.

The results of the ANOVAs indicate the statistical significance of the various sources of variation. However, the relative contribution of genotypic and environmental sources to the total observed variation in the three traits is also of interest (Table 5). In the combined year analyses, cultivar main effect and its interactions accounted for $66 \%, 63 \%$, and $57 \%$ of total variation in AA, TPH and fruit weight respectively. The majority of this was interaction variance for AA and TPH, whereas for fruit weight two thirds of it was from the cultivar main effect. Including fruit weight as a covariate in the analyses of AA and TPH reduced the contribution to total variance made by location and year within location, and increased the contribution of the cultivar main effect.

\section{Discussion}

These results are noteworthy principally for demonstrating significant cultivar $\times$ environment interactions for AA and TPH in blackberry and hybridberries. For these traits, simple cultivar and location effects were not significant and accounted for $<20 \%$ of total variance when both years' data were analyzed in a random effects model. Because only a single plot, albeit of up to three plants, of each cultivar was used at each location, it is not possible to separate effect of location from that of plant. Siriwoharn et al. (2004) found plot to plot variation in TPH to be negligible in 'Marion' when ripe fruit were picked from a completely random-

Table 3. Analyses of variance for total phenolic content among 12 blackberry and hybridberry cultivars harvested in New Zealand and Oregon in 2002 and 2003, without and with fruit weight as a covariate.

\begin{tabular}{lrrrrrrrr}
\hline & \multicolumn{3}{c}{ Mean } & \multicolumn{1}{c}{ Mean } \\
Source & df & squares & F & $P$ & df & squares & F & $P$ \\
\hline Fruit weight & -- & ----- & --- & --- & 1 & 164323 & 6442.63 & $<0.001$ \\
Cultivar (C) & 11 & 34639 & 1.27 & 0.302 & 11 & 52707 & 2.65 & 0.061 \\
Location (L) & 1 & 170088 & 1.85 & 0.267 & 1 & 1117 & 0.02 & 0.895 \\
Year (Y) within L & 2 & 71437 & 10.54 & 0.001 & 2 & 41845 & 8.81 & 0.002 \\
C× L & 11 & 27233 & 4.02 & 0.003 & 11 & 19911 & 4.19 & 0.002 \\
C $\times$ Y within L & 22 & 6777 & 7.82 & $<0.001$ & 22 & 4749 & 7.01 & $<0.001$ \\
Extract within C $\times$ Y within L & 48 & 867 & 33.98 & $<0.001$ & 47 & 677 & 26.56 & $<0.001$ \\
Residuals & 96 & 26 & & & 96 & 26 & & \\
\hline
\end{tabular}


Table 4. Analysis of variance for fruit weight among 12 blackberry and hybridberry cultivars harvested in New Zealand and Oregon in 2002 and 2003

\begin{tabular}{lrlrr}
\hline Source & \multicolumn{4}{c}{ Mean } \\
\hline Cultivar (C) & df & squares & \multicolumn{1}{c}{ F } & \multicolumn{1}{c}{$P$} \\
Location (L) & 11 & 17.44 & 8.68 & $<0.001$ \\
Year (Y) within L & 1 & 75.31 & 21.75 & 0.043 \\
C $\times$ L & 2 & 3.81 & 1.62 & 0.221 \\
C× Y within L & 11 & 2.01 & 0.85 & 0.596 \\
Residuals & 22 & 2.36 & 4.38 & $<0.001$ \\
\hline
\end{tabular}

ized design with three plants per plot. The changes we observed in cultivar rank (or scale) between locations and between years within location for AA and TPH suggest that accurate assessments of AA and TPH in blackberry and hybridberry genotypes will require testing over several years and locations. The genotypes used in this study have widely diverse genetic backgrounds and may not be equally suited for use as parents in a single breeding program. However, since blackberry and hybridberry breeding frequently takes advantage of compatibility among Rubus subgenera and employs interspecific hybridization, the results from this study are still expected to be applicable to assessments made in most breeding programs. Similar results were reported for blueberry (Vaccinium L.) by Connor et al. (2002), who noted cultivar $\times$ location interactions for TPH and anthocyanins, and cultivar $\times$ year within location interactions for AA, TPH, and anthocyanins among nine genotypes harvested in three locations over 2 years.

The reasons for the changes in AA and TPH within cultivar across years and across locations are not explained in this initial study, since the design did not intend to control, or define differences in, climate conditions and horticultural practices. As noted in the introduction, the phenolic compounds that contribute to AA are produced by plants for diverse functions, including stress response. Although the plants at both sites were maintained with good orchard practices, unrecognized stresses or conditions (e.g., ultraviolet radiation, heat stress, or infection) may have increased the production of phenolic compounds in one of the seasons or locations, with the degree of response being at least partially genetically determined. Our data suggest that between-location variation in AA and TPH is partly attributable to between-location differences in fruit weight, but these differences per se are

Table 5. Variance component distributions for antioxidant activity (AA) and total phenolic content (TPH) (unadjusted and adjusted for fruit weight), and fruit weight in fruit from 12 blackberry and hybridberry cultivars harvested in 2002 and 2003 in Oregon and New Zealand.

\begin{tabular}{|c|c|c|c|c|c|}
\hline \multirow[b]{3}{*}{ Component } & \multicolumn{5}{|c|}{ Percentage of total variation } \\
\hline & \multicolumn{2}{|c|}{ Unadjusted for fruit wt } & \multicolumn{2}{|c|}{ Adjusted for fruit wt } & \multirow[b]{2}{*}{ Fruit wt } \\
\hline & AA & $\mathrm{TPH}$ & AA & TPH & \\
\hline Cultivar (C) & 11.1 & 6.5 & 29.0 & 24.1 & 39.0 \\
\hline Location (L) & 4.3 & 11.5 & 0.0 & 0.0 & 30.8 \\
\hline Year (Y) within L & 22.0 & 19.0 & 15.0 & 16.0 & 1.4 \\
\hline $\mathrm{C} \times \mathrm{L}$ & 34.6 & 36.0 & 29.6 & 36.0 & 0.0 \\
\hline $\mathrm{C} \times \mathrm{Y}$ within $\mathrm{L}$ & 20.3 & 20.8 & 19.9 & 17.9 & 17.7 \\
\hline Extract within $\mathrm{C} \times \mathrm{Y}$ within $\mathrm{L}$ & 7.3 & 5.9 & 6.1 & 5.6 & --- \\
\hline Residuals & 0.4 & 0.4 & 0.4 & 0.4 & 11.1 \\
\hline
\end{tabular}

unlikely to account for the significant cultivar $\times$ environment interactions for AA and TPH, because neither the significance of the interaction components nor their contribution to total variance altered substantially with adjustment for fruit weight. As noted above, one of the limitations of our study was the use of single (one to three plant) plots. Greater replication could have improved the estimates of genotypic and environmental effects. Additional factors for which we did not adjust were differences in plant age within and between locations, and crop load. It is possible that these factors influenced fruit AA and TPH, but further studies are needed to determine their impact. By better defining those factors that strongly influence TPH (and AA) in fruit, we could possibly develop horticultural practices that increase AA in fruit (albeit more effectively in certain cultivars), without adversely affecting plant vigor or health.

The number of cultivars common to both locations and both years was relatively small $(n=12)$, which, despite their genetically diverse backgrounds, may have limited the among-cultivar differences in these traits. We observed 1.4-fold to 2.1-fold ranges in AA among cultivars within each location and each year. This is less than the 2.0-fold and 3.9-fold ranges that Clark et al. (2002) reported among blackberry genotypes harvested in Arkansas in 1999 ( $n=13$ genotypes) and $2000(n=15$ genotypes), using an oxygen radical absorbance capacity assay (ORAC). They also observed a 1.5-fold range in phenolics in 1999, and a 2.0-fold range in phenolics in 2000, which is similar to the 1.6-fold to 1.9-fold ranges obtained in this study, and the 1.5 -fold range reported by Siriwoharn et al. (2004). Thus, there is some evidence of greater variation among blackberry genotypes than we observed among our blackberries and hybridberries.

There was a high correlation $(r=0.97)$ between AA and TPH, when calculated on a cultivar-mean basis using data from each location and year. Similar high correlations were reported by Moyer et al. (2002) among 37 Rubus species and cultivars harvested in a single season $(r=0.90$ between TPH and FRAP). This figure included data from five Rubus species raspberries, and three black raspberry ( $R$. occidentalis $\mathrm{L}$. and hybrids) genotypes. Moyer et al. (2002) noted a lower correlation when data from 27 hybrid blackberries alone were considered $(r=0.75$ between TPH and FRAP). In their study of variation in AA with fruit developmental stage among berry cultivars, Wang and Lin (2000) reported a high correlation between TPH and AA as measured by ORAC ( $r=$ 0.996), in juice obtained from mature fruit from three blackberry cultivars. A high correlation between TPH and AA has been noted in other fruit, including berry fruit (Connor et al., 2002; Deighton et al., 2002) and tree fruit (Kim et al., 2003; Leontowicz et al., 2002). Many studies that report the relationship between AA and $\mathrm{TPH}$, including ours, used a FolinCiocalteu reagent-based method to determine TPH. However, this method measures phenolic and nonphenolic oxidizable substances (Singleton et al., 1999). Nonphenolic compounds, such as vitamin $\mathrm{C}$, can interfere with the determination, if present in the fruit extracts. Hence, if our extracts contained appreciable amounts of oxidizable nonphenolic compounds, the correlation 
between AA and true TPH might be slightly lower than 0.97.

Many berry fruit possess high concentrations of phenolic acids, anthocyanins, some flavonols, and other phenolic classes, which have antioxidant activity in vitro (Jovanovic et al., 1998; Rice-Evans and Miller, 1998). Vitamin C, folate, and carotenoids, which are nonphenolic compounds, possess AA as well, and while they are found in high concentration in some fruit, their concentrations in blackberry are not high compared to other fruit (USDA-ARS, 2004) and they probably do not contribute appreciably to the AA; however, we did not determine these compounds in our genotypes.

Fruit weight varied significantly among cultivars and among locations, but the relative fruit weight of the 12 cultivars did not vary between locations. However, cultivar ranking for fruit weight altered between years within location. Moyer et al. (2002) reported an approximate 3.7-fold range in fruit weight among 27 hybrid blackberries and a 3.9-fold range among five Rubus species blackberries harvested in a single year. This compares to the 1.7-fold to 2.5-fold ranges we observed in individual years in the two locations. Although large fruit size/weight is considered a desirable fruit quality in blackberry, both because of consumer preference and its impact on harvesting efficiency (Daubeny, 1996), the effects of location and year on fruit size variation do not appear to be well-documented. Caldwell and Moore (1982) suggested inheritance of fruit size in blackberry was quantitative, with partial dominance for small fruit size, based on progeny data from 12 seedling populations from crosses among small-, intermediate-, and large-fruited parents. They also reported broad sense and narrow sense heritability estimates of 0.76 and 0.62 , respectively, for blackberry fruit size, and thus there appears to be substantial additive genetic variation. Their estimates were based on a single year of data among the 12 seedling populations in one location, so they do not document location and year effects on this trait.

Antioxidant activity and TPH were significantly and inversely correlated with fruit weight, and analyses demonstrated the significance of fruit weight when used as a covariate assessing AA and TPH. Notably, when adjustment for fruit weight was made, cultivar effects accounted for a much greater proportion of total variation in AA and TPH than previously, while the proportion of variation attributable to location effects simultaneously decreased to zero. These findings suggest that between-location variation in AA or TPH, although not constituting a high proportion of total variation, could be largely explained by location effect on fruit weight, which is inversely related to AA and TPH. Additionally, the fact that the proportion of variation due to cultivar main effect increased when fruit weight was used as a covariate suggests that comparison of AA or TPH among cultivars that are distinguishable by different AA-fruit weight (or TPH-fruit weight) relationships can be made more precise by adjustment for fruit weight.

The negative correlation between AA and fruit size is of concern if the traits are genotypically correlated, since simultaneous progress in AA and fruit size in blackberries and hybridberries would be limited. Our study was not designed to investigate genotypic correlations. However, for red raspberry (R. idaeus L.), Connor et al. (2005) reported a negligible genotypic correlation of -0.07 between AA and fruit weight, despite finding a significant negative phenotypic correlation of -0.34 . If a low genotypic correlation can be confirmed in blackberry as well, it would favor the prospect of breeding for large fruit size and high AA simultaneously.

In blueberry, the high concentration of anthocyanins (relative to other phenolic antioxidants) and their confinement to the skin of the fruit might explain the inverse relationship reported between AA and fruit size (Connor et al., 2002), since the surface area increases less rapidly than the total volume of the fruit, and the high anthocyanin concentration appears to contribute substantially to the AA in blueberry. In blackberry and hybridberries, a similar explanation for the inverse relationship between fruit weight and AA is not evident. A skin:flesh partitioning of pigmentation is not observed in blackberries and hybridberries, and the contribution that anthocyanin content makes to AA may be less than that observed in blueberry. However, blackberries and hybridberries do possess a nonpigmented receptacle, and it is possible that with increasing fruit size this receptacle accounts for an increasing proportion of the total volume than the adherent drupelets. If the receptacle's concentration of phenolic compounds is lower than that of the drupelet flesh and skin, this might explain the relationship between fruit size/weight and AA we observed in this study. Another possible contributor to the relationship is increased production of phenolic compounds in response to a stress that is severe enough to adversely affect fruit growth, leading to smaller fruit with high levels of phenolic antioxidants. However, the generally healthy condition of the plants and fruit used in this study makes this an unlikely explanation for our data. If the increase in fruit size was due in large part to increase in water content, then dilution effect might explain the inverse relationship between fruit size and AA or TPH. Our study did not include determination of soluble solids or fruit dry weights, which would help to confirm or refute dilution effect. However, Siriwoharn et al. (2004) found a poor correlation between the mean SS and TPH of the 11 blackberry hybrids they studied ( $r$ $=0.11$, derived from their Table 7).

In the ANOVAs for AA and TPH, there was significant variation among extracts within cultivar; this accounted for $6 \%-7 \%$ of total variation. The mean square values for extracts within cultivar were quite small compared to those for the main effects and most of the interactions, and it is therefore unlikely that any of the calculated F-values would have been meaningfully altered if among-extract variation were reduced. The extracts were each based on $30 \mathrm{~g}$ of fruit (20 g were used for fruit harvested in OR in 2002), which, for the average fruit weight of $6.9 \mathrm{~g}$, represents only four or five fruit. If among-fruit variation in AA and TPH were substantial, a small number of fruit per extract could be the source of significant variation among extracts. Thus, those screening blackberry and hybridberry genotypes for AA or TPH might prefer using $>30 \mathrm{~g}$ fruit per extract to try to reduce amongextract variation.

In summary, our two-location and 2-year study of AA and TPH in 12 blackberry and hybridberry cultivars did not demonstrate significant among-cultivar and among-location variation, but indicated that variation between years within location was significant, and that genotype $\times$ environment interactions were significant. This suggests that optimal evaluation of genotypic performance for these traits should include assessment over several years and locations. The cultivars we evaluated display highly diverse interspecific backgrounds. As a group, they may not reflect a "typical" parental pool in a blackberry/hybridberry breeding program. But use of a complex array of species from the Rubus blackberry subgenera, (and from other Rubus subgenera) continues to be characteristic of blackberry and hybridberry breeding, and thus the results from this study are expected to be applicable to blackberry and hybridberry breeding evaluation and selection. 


\section{Literature Cited}

Bazzano,L.A., J.He, L.G. Ogden, C.M.Loria, S. Vupputuri,L. Myers, and P.K. Whelton. 2002. Fruit and vegetable intake and risk of cardiovascular disease in U.U. adults: The first National Health and Nutrition Examination Survey Epidemiologic Follow-up study. Amer. J. Clinical Nutr. 76:93-99.

Benzie, I.F.F. and J.J. Strain. 1996. The ferric reducing ability of plasma (FRAP) as a measure of "antioxidant power": The FRAP assay. Anal. Biochem. 239:70-76.

Block G., B. Patterson, and A. Subar. 1992. Fruit, vegetables and cancer prevention: A review of the epidemiological evidence. Nutr. Cancer 18:1-29.

Brown, L., E.B. Rimm, J.M. Seddon, E.L. Giovannucci, L. Chasan-Taber, D Spiegelman, W.C. Willett, and S.E. Hankinson. 1999. A prospective study of carotenoid intake and risk of cataract extraction in U.S. men. Amer. J. Clinical Nutr. 70:517-524.

Caldwell, J.D. and J.N. Moore. 1982. Inheritance of fruit size in the cultivated tetraploid blackberry [Rubus (Tourn.) L. subgenus Eubatus]. J. Amer. Soc. Hort. Sci. 107:628-631.

Cho, E., J.M. Seddon, B. Rosner, W.C. Willett, and S.E. Hankinson. 2004. Prospective study of intake of fruits, vegetables, vitamins, and carotenoids and risk of age-related maculopathy. Arch. Ophthalmology 122:883-892.

Clark, J.R., L. Howard, and S. Talcott. 2002. Antioxidant activity of blackberry genotypes. Acta Hort. 585:475-480.

Connor, A.M., J.J. Luby, C.B.S. Tong, C.E. Finn, and J.F. Hancock. 2002. Genotypic and environmental variation in antioxidant activity, total phenolic content, and anthocyanin content among blueberry cultivars. J. Amer. Soc. Hort. Sci. 127:89-97.

Connor, A.M., M.J. Stephens, H.K. Hall, and P.A. Alspach. 2005. Variation and heritabilities of antioxidant activity and total phenolic content estimated from a red raspberry factorial experiment. J. Amer. Soc. Hort. Sci. 130:403-411.

Coseteng, M.Y. and C.Y. Lee. 1987. Changes in apple polyphenoloxidase and polyphenol concentration in relation to degree of browning. J. Food Sci. 52:985-989.

Cotran, R.S., V. Kumar, T. Collins, and S.L. Robbins. 1999. Cellular pathology I: Cell injury and cell death, p. 1-30. In: R.S. Cotran, V. Kumar, T. Collins, and S.L. Robbins (eds.). Robbins pathologic basis of disease. $6^{\text {th }}$ ed. W.B. Saunders, Philadelphia.

Daubeny, H.A. 1996. Brambles, p. 109-190. In: J. Janick and J.N. Moore (eds.). Fruit breeding. vol. II. Vine and small fruits. Wiley, New York.

Deighton, N., R. Brennan, C. Finn, and H.V. Davies. 2000. Antioxidant properties of domesticated and wild Rubus species. J. Sci. Food Agr. 80:1307-1313.

Deighton, N., D. Stewart, H.V. Davies, P.T. Gardner, G.G. Duthie, W. Mullen, and A. Crozier. 2002. Soft fruit as sources of dietary antioxidants. Acta Hort. 585:459-465.

Goldberg, J., G. Flowerdew, E. Smith, J.A. Brody, and M.O. Tso. 1988. Factors associated with age-related macular degeneration. An analysis of data from the first National Health and Nutrition Examination Survey. Amer. J. Epidemiology 128:700-710.

Häkkinen, S.H., S.O. Kärenlampi, I.M. Heinonen, H.M. Mykkänen, and A.R. Törrönen. 1999. Content of the flavonols quercetin, myricetin, and kaempferol in 25 edible berries. J. Agr. Food Chem. 47:2274-2279.

Halvorsen, B.L., K Holte, M.C.W. Myhrstad, I. Barikmo, E. Hvattum, S.F. Remberg, A-B. Wold, K. Haffner, H. Baugerød, L.F. Andersen, Ø. Moskaug, D.R. Jacobs, Jr., and R. Blomhoff. 2002. A systematic screening of total antioxidants in dietary plants. J. Nutr. 132:461-471.

Herrmann, K. 1989. Occurrence and content of hydroxycinnamic and hydroxybenzoic acid compounds in foods. Crit. Rev. Food Sci. Nutr. 28:315-347.

Joshipura K.J., A. Ascherio, J.E. Manson, M.J. Stampfer, E.B. Rimm, F.E. Speizer, C.H. Hennekens, D. Spiegelman, and W.C. Willett. 1999. Fruit and vegetable intake in relation to risk of ischemic stroke. J. Amer. Medical Assn. 282:1233-1239.

Joshipura K.J., F.B. Hu, J.E. Manson, M.J. Stampfer, E.B. Rimm, F.E. Speizer, G. Colditz, A. Ascherio, B. Rosner, D. Spiegelman, and W.C. Willett. 2001. The effect of fruit and vegetable intake on risk for coronary heart disease. Ann. Internal Medicine 134:1106-1114.

Jovanovic, A.V., S. Steenken, M.G. Simic, and Y. Hara. 1998. Antioxidant properties of flavonoids: reduction potential and electron transfer reactions of flavonoid radicals, p. 137-161. In: C.A. Rice-Evans and L. Packer (eds.). Flavonoids in health and disease. Marcel Dekker, New York.

Kähkönen, M.P., A.I. Hopia, and M. Heinonen. 2001. Berry phenolics and their antioxidant activity. J. Agr. Food Chem. 49:4076-4082.
Kähkönen, M.P., A.I. Hopia, H.J. Vuorela, J-P. Rauhu, K. Pihlaja, T.S. Kujala, and M. Heinonen. 1999. Antioxidant activity of plant extracts containing phenolic compounds. J. Agr. Food Chem. 47:3954-3962.

Kim, D.O., O.K. Chun, Y.J. Kim, H.Y. Moon, and C.Y. Lee. 2003. Quantification of polyphenolics and their antioxidant capacity in fresh plums. J. Agr. Food Chem. 51:6509-6515.

Leontowicz, H., S. Gorinstein, A. Lojek, M. Leontowicz, M. Číž, R. SolivaFortuny, Y-S. Park, S-T. Jung, S. Trakhtenberg, and O. Martin-Belloso. 2002. Comparative content of some bioactive compounds in apples, peaches and pears and their influence on lipids and antioxidant capacity in rats. J. Nutr. Biochem. 13:603-610.

Miller, A.B., H.P. Altenburg, B. Bueno-de-Mesquita, H.C. Boshuizen, A. Agudo, F. Berrino, I.T. Graham, L. Janson, J. Linseisen, K. Overvad, T. Rasmuson, P. Vineis, A. Lukanova, N. Allen, P. Amiano, A. Barricarte, G. Berglund, H. Boeing, F. Clavel-Chapelon, N.E. Day, G. Hallmans, E. Lund, C. Martinez, C. Navarro, D. Palli, S. Panico, P.H.M. Peeters, J.R. Quirós, A. Tjønneland, R. Tumino, A. Trichopoulou, D. Trichopoulos, N. Slimani, and E. Riboli. 2004. Fruits and vegetables and lung cancer: Findings from the European Prospective Investigation into Cancer and Nutrition. Intl. J. Cancer 108:269-276.

Moyer, R.A., K.E. Hummer, C.E. Finn, B. Frei, and R.E. Wrolstad. 2002. Anthocyanins, phenolics, and antioxidant capacity in diverse small fruits: Vaccinium, Rubus, and Ribes. 2002. J. Agr. Food Chem. 50:519-525.

Ness, A.R. and J.W. Powles. 1997. Fruit and vegetables, and cardiovascular disease: A review. Intl. J. Epidemiology 26:1-13.

Ness, A.R. and J.W. Powles. 1999. The role of diet, fruit and vegetables and antioxidants in the aetiology of stroke. J. Cardiovascular Risk 6:229-234.

Proteggente, A.R., A.S. Pannala, G. Paganga, L. van Buren, E. Wagner, S. Wiseman, F. van de Put, C. Dacombe, and C.A. Rice-Evans. 2002. The antioxidant activity of regularly consumed fruit and vegetables reflects their phenolic and vitamin C composition. Free Radical Res. 36:217-233.

Rice-Evans, C.A. and N.J. Miller.1998. Structure-antioxidant activity relationships of flavonoids and isoflavonoids, p. 199-219. In: C.A. Rice-Evans and L. Packer (eds.). Flavonoids in health and disease. Marcel Dekker, New York.

Satterthwaite, F.E. 1946. An approximate distribution of estimates of variance components. Biometrics 2:110-114.

Sauvaget, C., J. Nagano, N. Allen, and K. Kodama. 2003. Vegetable and fruit intake and stroke mortality in the Hiroshima/Nagasaki Life Span Study. Stroke 34:2355-2360.

Sellapan, S., C.C. Akoh, and G. Krewer. 2002. Phenolic compounds and antioxidant capacity of Georgia-grown blueberries and blackberries. J. Agr. Food Chem. 50:2432-2438.

Singleton, V.L., R. Orthofer, and R.M. Lamuela-Raventos. 1999. Analysis of total phenols and other oxidation substrates and antioxidants by means of Folin-Ciocalteu reagent. Methods in Enzymology 299:152-178.

Siriwoharn, T., R.E. Wrolstad, C.E. Finn, and C.B. Pereira. 2004. Influence of cultivar, maturity, and sampling on blackberry (Rubus L. hybrids) anthocyanins, polyphenolics, and antioxidant properties. J. Agr. Food Chem. 52:8021-8030.

Smith-Warner, S.A., D. Spiegelman, S.S. Yaun, D. Albanes, W.L. Beeson, P.A. van den Brandt, D. Feskanich, A.R. Folsom, G.E. Fraser, J.L. Freudenheim, E. Giovannucci, R.A. Goldbohm, S. Graham, L.H. Kushi, A.B. Miller, P. Pietinen, T.E. Rohan, F.E. Speizer, W.C. Willett, and D.J. Hunter. 2003. Fruits, vegetables and lung cancer: A pooled analysis of cohort studies. Intl. J. Cancer 107:1001-1011.

Steel, R.G.D., J.H. Torrie, and D.A. Dickey. 1997. Principles and procedures of statistics: A biometrical approach. MacGraw-Hill, New York.

Steinmetz, K.A. and J.D. Potter. 1991. Vegetables, fruit and cancer. I. Epidemiology. Cancer Causes Control 2:325-357.

Steinmetz, K.A. and J.D. Potter. 1996. Vegetables, fruit and cancer prevention: A review. J. Amer. Dietetic Assn. 96:1027-1039.

U.S. Department of Agriculture, Agricultural Research Service. 2004. USDA national nutrient database for standard reference, Release 16. Nutrient Data Laboratory. 29 Nov. 2004. <http://www.nal.usda.gov/fnic/foodcomp/Data/ SR16/sr16.html>.

Wada, L. and B. Ou. 2002. Antioxidant activity and phenolic content of Oregon caneberries. J. Agr. Food Chem. 50:3495-3500.

Wang, H., G. Cao, and R.L. Prior. 1996. Total antioxidant capacity of fruits. J. Agr. Food Chem. 44:701-705.

Wang, S.Y. and H-S. Lin. 2000. Antioxidant activity in fruits and leaves of blackberry, raspberry, and strawberry varies with cultivar and developmental stage. J. Agr. Food Chem. 48:140-146. 